\title{
Prognostic Values of PET/CT Findings and Tumor/Patient Characteristics with Non-Small Cell Lung Cancer
}

\author{
Ozkan Demirhan ${ }^{1}$, Zinnet Barrin Balta ${ }^{2}$, Gunay Aydin Tosun², Serdar Erturan², Kerim Sonmezoglu ${ }^{3}$ \\ ${ }^{1}$ Department of Thoracic Surgery, Istanbul Bilim University, Istanbul, Turkey \\ ${ }^{2}$ Department of Chest Diseases, Istanbul University Cerrahpasa Medical School, Istanbul, Turkey \\ ${ }^{3}$ Department of Nuclear Medicine, Istanbul University Cerrahpasa Medical School, Istanbul, Turkey \\ Email: ozkandemirhan@hotmail.com
}

Received September 12, 2012; revised October 15, 2012; accepted October 30, 2012

\begin{abstract}
Background/Aim: Although numerous prognostic factors have been described for non-small cell lung cancer (NSCLC), there is still a requirement for better and non-invasive markers. FDG-PET is a non invasive diagnostic tool that is being used increasingly in the diagnosis of lung cancer. This study evaluates the prognostic values of PET/CT defined SUV measurements and other patient/tumor characteristics in newly diagnosed stage IIIB and IV NSCLC. Method: This retrospective study included 111 patients admitted between 2005 and 2006 with stage IIIB and IV NSCLC, whose diagnoses were verified with biopsy and staging performed with PET/CT. The prognostic values of standart uptake values (SUV) of the primary lesion on PET/CT, and other patient/tumor characteristics were analyzed using survival analysis. Results: SUV was found to be unrelated with survival. Only the presence of distant metastasis, type of metastasis (bone, brain, or the contralateral lung) and the type of radiotherapy used (curative or palliative) were found to be related to survival. SUV values in epidermoid carcinoma were found to be significantly higher compared to adenocarcinoma $(16.15 \pm 7.18$ and $12.32 \pm 5.52$, respectively, $\mathrm{p}=0.021)$. Conclusion: Our findings do not support that SUV of the primary lesion in inoperable NSCLC has a prognostic value with respect to survival. This condition may be explained by the inclusion of significantly advanced NSCLC patients who are known to have a low survival and a high mortality, and also the relatively small sampling size.
\end{abstract}

Keywords: Non-Small Cell Lung Cancer; Survival; Prognosis; Positron Emission Tomography (PET); FDG-PET

\section{Introduction}

Lung cancer is one of the most common malignant tumors in the world. Non-small cell lung cancer (NSCLC) comprises $80 \%$ of lung cancers. Most patients diagnosed with NSCLC present at local advanced (stage IIIB) or metastatic (stage IV) stages [1,2]. These patients have a poor natural course and short mean survival.

There are more than 150 prognostic factors for lung cancer related to tumor, patient and environmental factors, described in the literature. Tumor stage at admission (TNM), patient performance and weight loss are the most significant factors that play a role in survival [3]. Molecular markers and the doubling time of tumor diameter are also considered to be closely related to prognosis [4]. In addition, it has been suggested that the ratio between serum levels of trace elements copper and zinc $(\mathrm{Cu} / \mathrm{Zn})$ can be used as a prognostic factor, where an increase could act as a poor prognostic factor [5]. Researches for new prognostic determinants are still carried out.

Tumor cells have increased consumption and uptake of glucose or its analogues (deoxyglucose) [6]. Glucose metabolism tracing is carried out using F-18 labeled fluoro-2-deoxy-D-glucose (FDG). F-18 FDG accumulates in the cell because it cannot be catabolized [7]. Thus tissues with increased metabolism can be detected with positron emission tomography (PET). The most important feature of the PET method is its demonstration of metabolic activity rather than anatomic detail. PET is a quantitative method that measures, according to time and spatial location, the radiation emitted from positron emitting radiopharmaceutical agent. In recent years, the clinical use of FDG-PET as a noninvasive diagnostic method has become more common [7]. FDG-PET is the standart imaging method for staging, evaluation, treatment and follows up in patients with lung cancer. FDG-PET also has an important role in determining survival after treatment in NSCLC patients. FDG uptake intensity is stated with a semiquantitative value named "standart uptake value" (SUV). An SUV $>2.5$ shows that the lesion being examined is hypermetabolic. It is believed that high SUV values in patients with NSCLC are correlated with high tumor division rates $[8,9]$, and poor prognostic factors $[7,10-13]$. 
In our study, the relationship between the SUV of the primary lesion on PET/CT and prognosis, and also the relation between tumor diameter and histologic subgroups and survival were assessed in patients with recently diagnosed stage IIIB and IV NSCLC. In addition, the correlation between survival and age, sex, radiotherapy (RT) dose, response to chemotherapy (CT), and the site of metastasis were investigated.

\section{Methods}

\subsection{Patients and Collection of Data}

This retrospective study included 111 (92 male, 19 female) patients who presented to our hospital between 2005 and 2006 with stage IIIB and IV NSCLC. The diagnosis of NSCLC was verified with biopsy, and staging was made with PET/CT. Patients with stage IV disease who underwent metastasectomy were not included in the study. The metastases were verified with biopsies in seven of the lesions described as metastases on PET/CT. In three other patients metastases were confirmed with MRI. The remaining 61 patients were accepted as stage 4 based on the involvement seen in PET/CT and cranial MRI. All non-T4 patients with lymph node involvement but without metastasis in PET/CT and cranium MRI underwent a mediastinoscopy. The data including the date of diagnosis established with biopsy, cell type, age, sex, presence of a second malignancy, site of metastasis, SUV measurement of the primary lesion, tumor diameter, date of death, CT regimen, presence of RT and if present whether it was palliative or curative, history of cancer in the family, smoking history, and performance conditions were recorded. In addition, the performance scales of patients who underwent chemotherapy and/or radiotherapy were determined according to ECOG (Eastern Cooperative Oncology Group) [14]. Patients in ECOG 0-2, with adequate bone marrow function (neutrophils $>$ $1500 / \mathrm{mm}^{3}$, thrombocytes $\left.>100.000 / \mathrm{mm}^{3}, \mathrm{Hb}>10 \mathrm{gr} / \mathrm{dl}\right)$ and adequate renal function (serum creatinine $<1.5 \mathrm{mg} / \mathrm{dl}$, creatinine clearance $>60 \mathrm{ml} / \mathrm{min}$ ) received chemotherapy. The response to chemotherapy was assessed with chest $\mathrm{X}$ rays in every cycle, and with computer tomography after the third and sixth cycles according to the World Health Organization (WHO) criteria [15]. Chemotherapy was continued in patients who had stable disease or response during the follow up. Toxicity evaluation was done according to WHO criteria [15].

\subsection{PET/CT Imaging}

PET/CT images were obtained in two separate centers. Biograph LSO HI-REZ integrated PET/CT by Siemens was used for imaging. The images were evaluated by nuclear medicine specialists. Solid food intake was discontinued approximately 12 hours prior to PET proce- dure, however the patients were allowed to drink water and take their medicine. Patients with plasma glucose levels under $200 \mathrm{mg} / \mathrm{dl}$ received an intravenous injection of 18 FDG $(370 \mathrm{MBq})$, and one hour later images were taken from the cranial base to the upper part of the femur in seven separate bed positions. Three dimensional coronal, sagital and transverse planes were combined. SUV was calculated in all FDG collections that were considered to have abnormal appearance, values $>2.5$ were accepted malignant. All patients were staged using PET/ $\mathrm{CT}$ and other imaging methods.

\subsection{Statistical Analysis}

Evaluation of the data was made with SPSS for Windows 10.0 statistical pack; and comparisons were made with chi-square, student's t test and Kaplan Meier analysis. P $<0.05$ was accepted as significant.

\section{Results}

There were 19 females (17.1\%), and 92 males (82.9\%). Mean age was $59.56 \pm 8.98$ (range $=36-79)$. Seventy two (63.9\%) of the patients were stage IV, and $39(36.1 \%)$ were stage IIIB.

The histologic subtypes were as follows: NSCLC (unspecified) 16 (14.4\%), epidermoid carcinoma $45(40.5 \%)$, adenocarcinoma 41 (36.9\%), large cell carcinoma $1(0.9 \%)$, neuroendocrine carcinoma $1(0.9 \%)$, adenosquamous cancer 3 (2.7\%), bronchoalveolar carcinoma $2(1.8 \%)$, carcinoma showing neuroendocrine differentiation $1(0.9 \%)$, pleomorphic carcinoma $1(0.9 \%)$.

There was no statistical difference between patients above versus below age 60 years when compared with respect to mean survival time (Table 1). When sex and survival were compared, women had a slightly longer survival, however this was not statistically significant (Table 2).

The statistical relationship between tumor characteristics (location, diameter, T, N, M) and survival are given

Table 1. Relationship between age and survival.

\begin{tabular}{cccccc}
\hline Age & $\mathrm{N}$ & $\begin{array}{c}\text { Mean } \\
\text { (months) }\end{array}$ & $\begin{array}{c}\text { SE } \\
\text { (months) }\end{array}$ & $\begin{array}{c}\text { Median } \\
\text { (months) }\end{array}$ & $\mathrm{p}$ \\
\hline <age 60 & 49 & 11 & 1 & 10 & \\
>age 60 & 62 & 11 & 1 & 9 & 0.620 \\
\hline
\end{tabular}

Table 2. Relationship between sex and survival.

\begin{tabular}{cccccc}
\hline Sex & $\mathrm{N}$ & $\begin{array}{c}\text { Mean } \\
\text { (months) }\end{array}$ & $\begin{array}{c}\text { SE } \\
\text { (months) }\end{array}$ & $\begin{array}{c}\text { Median } \\
\text { (months) }\end{array}$ & $\mathrm{p}$ \\
\hline Male & 92 & 11 & 1 & 9 & \\
Female & 19 & 12 & 2 & 10 & 0.624 \\
\hline
\end{tabular}


in Table 3. Comparison between patients who had curative or palliative radiotherapy showed that the survival times were 12 months and 6 months, respectively, and the difference was statistically significant (Table 4). Analysis of correlation between response to chemotherapy and survival showed that the survival was 11 months in patients with partial response, 12 months in complete response, 9 months in those who remained stable, and 8 months in those who progressed. These figures were not significant (Table 5). Patients classified 1 and 2 on the ECOG performance scale were compared with respect to survival. Survival of patients grouped as ECOG-1 and ECOG-2 were 9 and 8 months, respectively. The difference was insignificant (Table 6). The relationship between SUV measurements of the primary mass and survival was not significant (Table 7). When the relationship between cellular subtype and SUV measurements were assessed, epidermoid cancer was ranked first, with SUV 16.14. This was significantly higher statistically when compared with adenocarcinoma (Table 8). Statistical evaluation was not made in other cell types due to inadequate number of patients. When the relationship between metastatic status and survival were assessed, survival was significantly higher in patients without metastasis (Table 9). Analysis for metastasis type (bone,

Table 3. Relationship between tumor characteristics and survival.

\begin{tabular}{|c|c|c|c|c|c|}
\hline $\begin{array}{c}\mathrm{TM} \\
\text { characteristics }\end{array}$ & $\mathrm{N}$ & $\begin{array}{c}\text { Mean } \\
\text { (months) }\end{array}$ & $\begin{array}{c}\text { SE } \\
\text { (months) }\end{array}$ & $\begin{array}{l}\text { Median } \\
\text { (months) }\end{array}$ & $\mathrm{p}$ \\
\hline \multicolumn{6}{|c|}{ Tumor Location } \\
\hline Right & 58 & 12 & 1 & 10 & \multirow{2}{*}{0.141} \\
\hline Left & 53 & 9 & 1 & 8 & \\
\hline \multicolumn{6}{|c|}{ Tumor Diameter } \\
\hline$\leq 3 \mathrm{~cm}$ & 54 & 15 & 3 & 16 & \multirow{2}{*}{0.226} \\
\hline$>3 \mathrm{~cm}$ & 57 & 10 & 1 & 10 & \\
\hline \multicolumn{6}{|c|}{ T Status } \\
\hline 1 & 5 & 11 & 1 & 12 & \multirow{4}{*}{0.644} \\
\hline 2 & 49 & 10 & 1 & 9 & \\
\hline 3 & 16 & 10 & 2 & 8 & \\
\hline 4 & 41 & 11 & 1 & 8 & \\
\hline \multicolumn{6}{|c|}{ N Status } \\
\hline 0 & 22 & 11 & 1 & 10 & \multirow{4}{*}{0.834} \\
\hline 1 & 2 & 12 & 1 & 12 & \\
\hline 2 & 52 & 11 & 1 & 9 & \\
\hline 3 & 35 & 10 & 2 & 8 & \\
\hline \multicolumn{6}{|c|}{ M Status } \\
\hline Absent & 39 & 14 & 1 & 12 & \multirow{2}{*}{0.003} \\
\hline Present & 72 & 9 & 1 & 8 & \\
\hline
\end{tabular}

Table 4. Relationship between curative and palliative radiotherapy and survival.

\begin{tabular}{cccccc}
\hline RT & $\mathrm{N}$ & $\begin{array}{c}\text { Mean } \\
\text { (months) }\end{array}$ & $\begin{array}{c}\text { SE } \\
\text { (months) }\end{array}$ & $\begin{array}{c}\text { Median } \\
\text { (months) }\end{array}$ & $\mathrm{p}$ \\
\hline Curative & 25 & 15 & 2 & 12 & 0.030 \\
Palliative & 86 & 9 & 1 & 6 & \\
\hline
\end{tabular}

Table 5. Relationship between response to chemotherapy and survival.

\begin{tabular}{cccccc}
\hline $\begin{array}{c}\text { Response to } \\
\text { CT }\end{array}$ & $\mathrm{N}$ & $\begin{array}{c}\text { Mean } \\
\text { (months) }\end{array}$ & $\begin{array}{c}\text { SE } \\
\text { (months) }\end{array}$ & $\begin{array}{c}\text { Median } \\
\text { (months) }\end{array}$ & $\mathrm{p}$ \\
\hline Partial & 21 & 12 & 1 & 11 & \\
Complete & 19 & 14 & 4 & 12 & 0.417 \\
Stable & 32 & 10 & 2 & 9 & \\
Progression & 38 & 10 & 1 & 8 & \\
\hline
\end{tabular}

Table 6. Relationship between ECOG performance and survival.

\begin{tabular}{cccccc}
\hline ECOG & $\mathrm{N}$ & $\begin{array}{c}\text { Mean } \\
\text { (months) }\end{array}$ & $\begin{array}{c}\text { SE } \\
\text { (months) }\end{array}$ & $\begin{array}{c}\text { Median } \\
\text { (months) }\end{array}$ & $\mathrm{p}$ \\
\hline 1 & 19 & 11 & 1 & 9 & \\
2 & 16 & 10 & 2 & 8 & 0.846 \\
\hline
\end{tabular}

Table 7. Relationship between SUV of the primary mass and survival.

\begin{tabular}{cccccc}
\hline SUV & N & $\begin{array}{c}\text { Mean } \\
\text { (months) }\end{array}$ & $\begin{array}{c}\text { SE } \\
\text { (months) }\end{array}$ & $\begin{array}{c}\text { Median } \\
\text { (months) }\end{array}$ & $\mathrm{p}$ \\
\hline $\mathrm{SUV} \leq 10$ & 29 & 13 & 2 & 9 & \\
$\mathrm{SUV} 10-20$ & 46 & 11 & 1 & 10 & 0.773 \\
$\mathrm{SUV} \geq 20$ & 15 & 10 & 1 & 10 & \\
\hline
\end{tabular}

Table 8. Relationship between cell subtypes and SUV.

\begin{tabular}{ccccc}
\hline Cell Type & $\mathrm{N}$ & Mean & $\mathrm{SD}$ & $\mathrm{p}$ \\
\hline Epidermoid ca & 33 & 16.1485 & 7.3830 & \\
Adenocarcinoma & 32 & 12.3159 & 5.5214 & 0.021 \\
\hline
\end{tabular}

brain, contralateral lung) showed that survival was significantly lower in bone metastasis (Table 10).

\section{Discussion}

NSCLC comprises $80 \%$ of lung cancers and mean 5 year survival is between $10 \%-15 \%$. The most important factor that affects prognosis in lung cancer is the stage of the disease. More than 150 other prognostic factors that affect survival in NSCLC have been described in the literature $[3,4]$. Apart from the stage, performance condition of the patient and weight loss carry a secondary significance 
Table 9. Relationship between metastasis type and its extent.

\begin{tabular}{cccccc}
\hline $\begin{array}{c}\text { Extent of } \\
\text { Metastasis }\end{array}$ & $\mathrm{N}$ & $\begin{array}{c}\text { Mean } \\
\text { (months) }\end{array}$ & $\begin{array}{c}\text { SE } \\
\text { (months) }\end{array}$ & $\begin{array}{c}\text { Median } \\
\text { (months) }\end{array}$ & $\mathrm{P}$ \\
\hline $\begin{array}{c}\text { No } \\
\text { Metastasis }\end{array}$ & 39 & 15 & 1 & 21 & \\
Isolated & 12 & 10 & 1 & 8 & 0.0009 \\
Multiple & 60 & 7 & 1 & 5 & \\
\hline
\end{tabular}

Table 10. Relationship between metastasis type and survival.

\begin{tabular}{ccccc}
\hline $\begin{array}{c}\text { Metastasis } \\
\text { Type }\end{array}$ & $\begin{array}{c}\text { Mean } \\
\text { (months) }\end{array}$ & $\begin{array}{c}\text { SE } \\
\text { (months) }\end{array}$ & $\begin{array}{c}\text { Median } \\
\text { (months) }\end{array}$ & P \\
\hline Bone & 7 & 1 & 4 & \\
Brain & 12 & 3 & 9 & 0.0479 \\
$\begin{array}{c}\text { Contralateral } \\
\text { Lung }\end{array}$ & 14 & 2 & 12 & \\
\hline
\end{tabular}

among prognostic factors.

In our study mean survival decreased as the tumor stage increased, which was similar to the literature. When $\mathrm{T}, \mathrm{N}$, and $\mathrm{M}$ are compared between each other, mean survival times for $\mathrm{T}$ were as follows: 12 months for T1, 9 months for T2, and 8 months for T3 and T4. In the literature, nodal involvement is the most important prognostic factor for survival. Mean survival in our study were 12 months for N1, 9 months for N2, and 6 months for N3. The survival decreased as lymphatic involvement increased, a finding also similar to previous reports. When metastatic versus non-metastatic lung cancer groups were compared, mean survival times for M0 and M1 were 12 months and 8 months, respectively. This difference was statistically significant $(\mathrm{p}<0.005)$.

It is stated that prognosis worsens as SUV increases. Berghmans et al. found that high SUV was a poor prognostic factor for survival [16]. Goodgame et al. performed a retrospective study to determine the prognostic significance of SUV in 136 stage I NSCLC patients, and the threshold SUV was accepted as 5.5 [17]. Thirty two of the 136 patients had a recurrence of malignancy during the follow up period of 46 months. The tendency for tumor recurrence was three times greater in patients with SUV above 5.5. The 5 year survival was $74 \%$ in patients with SUV under 5.5, and 53\% above $5.5(\mathrm{p}=0.006)$. Decoster et al. performed PET before and after 3 cycles of neoadjuvant chemotherapy and subsequent consolidation radiotherapy in 31 inoperable stage III patients [18]. All patients had increased FDP uptake prior to initiation of treatment (mean SUV $=11.3$ ). Following 3 cycles of neoadjuvant chemotherapy, 10 patients had $\mathrm{SUV}<2.5$, which was accepted as complete metabolic response. Following treatment, when this group of 10 patients were compared with patients having SUV greater than 2.5 , it was seen that the average times to progression (disease free period) were 19.9 and 9.8 months, and overall survival times were 49 and 14.4 months, respectively. Ahuja et al. measured SUV in 155 patients with NSCLC. Mean survival was 25 months in $118(76 \%)$ patients with SUV below 10, whereas it was 11 months in $37(24 \%)$ in patients with SUV above $10(\mathrm{p}=0.0049)$. In multivariate analysis, SUV above 10 provided the best prognostic information, independent of the clinical stage and lesion size [12]. In a study of 214 advanced stage cancer (stage IIIA, IIIB, IV) Hoang et al. used a median threshold SUV of 11.1, and did not find a significant difference in the survival times of patients having SUVs above and below this threshold (mean survival 16 and 12 months) [19]. In our study, we did not find a statistically significant correlation between the SUV and prognosis and survival. A possible explanation for this finding is that NSCLC patients with advanced stage (stage IIIB and IV) disease have low survival and high mortality rates, this precludes a correlation between survival and SUV.

In our patients, SUV was found to be higher in epidermoid carcinoma compared to other subgroups. In a study involving 176 patients, Tsutani et al. found that SUV was higher in epidermoid carcinoma compared to adenocarcinoma, however increased SUV was a more powerful indicator of poor prognosis in adenocarcinoma than epidermoid carcinoma [20]. This discrepancy may be explained by glucose metabolism. Previous studies have shown that increased tumor FDG may be related to overexpression of GLUT-1 (glucose transfer). Ito et al. reported that GLUT-1 overexpression was $100 \%$ in epidermoid carcinoma and 58\% in adenocarcinoma [21]. This difference in GLUT-1 may explain why epidermoid carcinoma has a higher SUV than adenocarcinoma.

The age for detection of lung cancer ranges between 50 and 80 in the literature [22]. Lung cancer is rare (1\% $6 \%$ ) under age 45 . According to previous studies, the disease is detected at a later stage and the prognosis is worse in lung cancer patients at or above age 45 [23,24]. On the other hand, there are other studies which show that survival in both groups is similar, or better in older patients [23]. Primary reasons for this conflict include the inadequate number of patients recruited into the studies, the paucity of patients who are given the chance of surgery, and differences between staging. Our study did not find age to be a significant prognostic factor (p: 0.3).

There numerous studies reporting that females have better prognosis than males $[25,26]$. It is still unclear why the female sex has a longer survival than male sex. In our study, mean survival was 10 months in females, and 9 months in males (p: 0.6).

\section{Conclusion}

We tried to determine whether the SUV measurements 
on PET-CT, which is used in the systemic screening and staging of lung cancer, showed a difference with respect to age, sex, and cell type of NSCLC, and whether this SUV measurement could be used in the estimation of prognosis and survival. Although there are studies in favor of this possibility, our findings did not support the use of SUV as a prognostic factor. Possible causes include the short survival and high mortality rates of NSCLC patients, the paucity of patients or that SUV may lack a prognostic significance.

\section{REFERENCES}

[1] D. M. Geddes, "The Natural History of Lung Cancer: A Review Based on Rates of Tumour Growth," British Journal of Diseases of the Chest, Vol. 73, No. 1, 1979, pp. 1-17. doi:10.1016/0007-0971(79)90002-0

[2] S. G. Spiro and G. A. Silvestri, "One Hundred Years of Lung Cancer," American Journal of Respiratory and Critical Care Medicine, Vol. 172, No. 5, 2005, pp. 523529. doi:10.1164/rccm.200504-531OE

[3] D. Michael, M. D. Brundage, D. Davies, et al., "Prognostic Factors in Non-Small Lung Cancer: A Decade of Progress," Chest, Vol. 122, No. 3, 2002, pp. 1037-1057. doi:10.1378/chest.122.3.1037

[4] B. E. Johnson, "Biologic and Molecular Prognostic Factors Impact on Treatment of Patients with Non-Small Cell Lung Cancer," Chest, Vol. 107, No. 6 Supplement, 1995, pp. 287S-290S.

doi:10.1378/chest.107.6_Supplement.287S

[5] O. Demirhan, A. Demirkaya, E. Ersen, et al., "Analysis of the Alterations of Trace Elements in Plasma and Tissue, in Lung Cancer," Tuberküloz ve Toraks Dergisi, Vol. 58, No. 1, 2010, pp. 53-58.

[6] E. K. Pauwels, M. J. Riberio, J. H. Stoot, et al., "FDG Accumulation and Tumour Biology," Nuclear Medicine and Biology, Vol. 25, No. 4, 1998, pp. 317-322. doi:10.1016/S0969-8051(97)00226-6

[7] K. Sonmezoglu, "The Use of FDG-PET Scanning in Lung Cancer," Tuberkuloz ve Toraks Dergisi, Vol. 53, No. 1, 2005, pp. 94-112.

[8] F. G. Duhaylongsod, V. J. Lowe, E. F. Patz Jr., et al., "Lung Tumor Growth Correlates with Glucose Metabolism Measured by Fluoride-18 Fluorodeoxyglucose Positron Emission Tomography," The Annals of Thoracic Surgery, Vol. 60, No. 5, 1995, pp. 1348-1352. doi:10.1016/0003-4975(95)00754-9

[9] H. Vesselle, R. A. Schmidt, J. M. Pugsley, et al., "Lung Cancer Proliferation Correlates with [F-18] Fluorodeoxyglucose Uptake by Positron Emission Tomography," Clinical Cancer Research, Vol. 6, No. 10, 2000, pp. 38373844.

[10] R. Sasaki, R. Komaki, H. Macapinlac, et al., " $\left[{ }^{18} F\right]$ Fluorodeoxyglucose Uptake by Positron Emission Tomography Predicts Outcome of Non-Small-Cell Lung Cancer," Journal of Clinical Oncology, Vol. 23, No. 6, 2005, pp. 1136-1143. doi:10.1200/JCO.2005.06.129
[11] J. F. Vansteenkiste, S. G. Stroobants, P. J. Dupont, et al., "Prognostic Importance of the Standardized Uptake Value on (18)F-Fluoro-2-Deoxy-Glucose-Positron Emission Tomography Scan in Non-Small-Cell Lung Cancer: An Analysis of 125 Cases. Leuven Lung Cancer Group," Journal of Clinical Oncology, Vol. 17, No. 10, 1999, pp. 3201-3206.

[12] V. Ahuja, R. E. Coleman, J. Herndon, et al., "The Prognostic Significance of Fluorodeoxyglucose Positron Emission Tomography Imaging for Patients with Nonsmall Cell Lung Carcinoma," Cancer, Vol. 83, No. 5, 1998, pp. 918-924. doi:10.1002/(SICI)1097-0142(19980901)83:5<918::AIDCNCR17>3.0.CO;2-Y

[13] K. Dhital, C. A. B. Saunders, P. T. Seed, et al., " $\left[{ }^{18} F\right]$ Fluorodeoxyglucose Positron Emission Tomography and Its Prognostic Value in Lung Cancer," European Journal of Cardiothoracic Surgery, Vol. 18, No. 4, 2000, pp. 425 428. doi:10.1016/S1010-7940(00)00535-2

[14] M. M. Oken, R. H. Creech, J. Horton, et al., "Toxicity and Response Criteria of the Eastern Cooperative Oncology Group," American Journal of Clinical Oncology, Vol. 5, No. 6, 1982, pp. 649-655. doi:10.1097/00000421-198212000-00014

[15] World Health Organization, "WHO Handbook for Reporting Results of Cancer Treatment," World Health Organization, Publication, Genova, 1979, pp. 16-21.

[16] M. Paesmans, T. Berghmans, M. Dusart, et al., "Primary Tumor Standardized Uptake Value Measured on Fluorodeoxyglucose Positron Emissinon Tomography Is of Prognostic Value for Survival in Non-Small Cell Lung Cancer: Update of a Systematic Review and Meta-Analysis by the European Lung Cancer Working Party for the International Association for the Study of Lung Cancer Staging Project," Journal of Thoracic Oncology, Vol. 5, No. 5, 2008, pp. 612-619.

[17] B. Goodgame, G. A. Pillot, et al., "Prognostic Value of Preoperative Positron Emission Tomography in Resected Stage I Non-Small Cell Lung Cancer," Journal of Thoracic Oncology, Vol. 3, No. 2, 2008, pp. 130-134. doi:10.1097/JTO.0b013e318160c122

[18] L. Decoster, D. Schallier, H. Everaert, et al., "Complete Metabolic Tumour Response, Assessed by ${ }^{18}$ Fluorodeoxyglucose Positron Emission Tomography $\left({ }^{18}\right.$ FDG-PET), after Induction Chemotheraphy Predicts a Favourable Outcome in Patients with Locally Advanced Non-Small Cell Lung Cancer (NSCLC)," Lung Cancer, Vol. 62, No. 1, 2008, pp. 55-61. doi:10.1016/j.lungcan.2008.02.015

[19] J. K. Hoang, L. F. Hoagland, R. E. Coleman, et al., "Prognostic Value of Fluorine-18 Fluorodeoxyglucose Positron Emission Tomography Imaging in Patients with Advanced-Stage Non-Small-Cell Lung Carcinoma," Journal of Clinical Oncology, Vol. 26, No. 9, 2008, pp. 14591464. doi:10.1200/JCO.2007.14.3628

[20] Y. Tsutani, Y. Miyata, K. Misumi, et al., "Difference in Prognostic Significance of Maximum Standardized Uptake Value on [18F]-Fluoro-2-Deoxyglucose Positron Emission Tomography between Adenocarcinoma and Squamous Cell Carcinoma of the Lung," Japanese Journal of Clinical Oncology, Vol. 41, No. 7, 2011, pp. 890- 
896. doi:10.1093/jico/hyr062

[21] T. Ito, Y. Noguchi, S. Satoh, et al., "Expression of Facilitative Glucose Transporter Isoforms in Lung Carcinomas: Its Relation to Histologic Type, Differentiation Grade, and Tumor Stage," Modern Pathology, Vol. 11, No. 5, 1998, pp. 437-443.

[22] W. C. Nugent, M. T. Edney, P. G. Hammerness, et al., Non-Small Cell Lung Cancer at the Extremes of Age: Impact on Diagnosis and Treatment," The Annals of Thoracic Surgery, Vol. 63, No. 1, 1997, pp.193-197. doi:10.1016/S0003-4975(96)00745-X

[23] S. Ramalingam, K. Pawlish, S. Gadgeel, et al., "Lung Cancer in Young Patients: Analysis of a Surveillance, Epidemiology and Results Database," Journal of Clinical Oncology, Vol. 16, No. 2, 1998, pp. 651-767.
[24] C. M. Tsai, R. P. Perng and W. L. Huang, "Lung Cancer in Young Chinese," Cancer Detection and Prevention, Vol. 11, No. 3-6, 1988, pp. 235-238.

[25] M. R. Palomares, J. W. Sayre, K. C. Shekar, et al., "Gender Influence on Weight-Loss Pattern and Survival of Non-Small Cell Lung Carcinoma Patients," Cancer, Vol. 78, No. 10, 1996, pp. 2119-2126. doi:10.1002/(SICI)1097-0142(19961115)78:10<2119::AI D-CNCR12>3.0.CO;2-1

[26] R. J. Cerfolio, A. S. Bryant, E. Scott, et al., "Women with Pathologic Stage I, II, and III Non-Small Cell Lung Cancer Have Better Survival than Men," Chest, Vol. 130, No. 6, 2006, pp. 1796-1799. doi:10.1378/chest.130.6.1796. 